\title{
Papers
}

\section{Randomised trial of heroin maintenance programme for addicts who fail in conventional drug treatments}

\author{
Thomas V Perneger, Francisco Giner, Miguel del Rio, Annie Mino
}

\begin{abstract}
Objective: To evaluate an experimental heroin maintenance programme.

Design: Randomised trial.

Setting: Outpatient clinic in Geneva, Switzerland. Subjects: Heroin addicts recruited from the community who were socially marginalised and in poor health and had failed in at least two previous drug treatments.

Intervention: Patients in the experimental programme $(n=27)$ received intravenous heroin and other health and psychosocial services. Control patients $(n=24)$ received any other conventional drug treatment (usually methadone maintenance).

Main outcome measures: Self reported drug use, health status (SF-36), and social functioning. Results: 25 experimental patients completed 6 months in the programme, receiving a median of $480 \mathrm{mg}$ of heroin daily. One experimental subject and 10 control subjects still used street heroin daily at follow up (difference 44\%; 95\% confidence interval $16 \%$ to $71 \%$ ). Health status scores that improved significantly more in experimental subjects were mental health $(0.58 \mathrm{SD} ; 0.07$ to 1.10$)$, role limitations due to emotional problems ( $0.95 \mathrm{SD} ; 0.11$ to 1.79$)$, and social functioning (0.65 SD; 0.03 to 1.26). Experimental subjects also significantly reduced their illegal income and drug expenses and committed fewer drug and property related offences. There were no benefits in terms of work, housing situation, somatic health status, and use of other drugs. Unexpectedly, only nine (38\%) control subjects entered the heroin maintenance programme at follow up.

Conclusions: A heroin maintenance programme is a feasible and clinically effective treatment for heroin users who fail in conventional drug treatment programmes. Even in this population, however, another attempt at methadone maintenance may be successful and help the patient to stop using injectable opioids.
\end{abstract}

\section{Introduction}

Many harmful consequences of heroin use stem from the illegal status of street drugs. ${ }^{1-3}$ Drug substitution programmes may alleviate these consequences, ${ }^{4}$ but not all addicts benefit: many continue using street drugs, others drop out, others never enrol. Addicts may fail in oral substitution programmes because they need the "high" caused by heroin injection or the ritual of preparing and injecting the drug. Programmes which provide intravenous heroin may reach such addicts..$^{5-12}$

In Switzerland several programmes involving provision of intravenous opiates were started in 1992 $5 .{ }^{13}$ Most were evaluated in a before and after design. Only the Geneva heroin maintenance programme was conceived as a randomised trial: eligible addicts were randomised either to immediate admission or to a 6 month waiting list during which time they could receive any other available drug treatment. The research question was whether the experimental programme would improve participants' illegal drug use, health, and social functioning.

\section{Methods}

\section{Study design and sample}

This randomised trial compared outcomes at 6 months in patients allocated to immediate versus delayed admission to the heroin maintenance programme. The planned sample size was two groups of 40 patients. Programme and study procedures were approved by ethics committees in Geneva and Berne.

Eligibility criteria were residence in the canton of Geneva since June 1994, age $\geqslant 20$ years, addiction to intravenous heroin for $\geqslant 2$ years, daily consumption of opiates, social distress or poor health or both, due to drug use, two or more previous unsuccessful attempts at drug treatment, participation in evaluation, and giving up driving on starting heroin maintenance.

Information about the programme was disseminated through drug abuse treatment centres. Interested people were screened on the telephone by a psychiatrist (FG), and those who seemed eligible were invited to an initial visit. During this visit the psychiatrist confirmed the patient's eligibility, explained programme procedures, obtained informed consent, performed the baseline assessment, and allocated the patient to either immediate or delayed admission by using computer generated random numbers placed in sealed envelopes.

\section{Experimental programme}

The programme clinic was established in September 1995 by the division of substance abuse, Geneva University Hospitals, in central Geneva. Staff included

\author{
Institute of Social \\ and Preventive \\ Medicine, \\ University of \\ Geneva Medical \\ School, CH-1211 \\ Geneva 4, \\ Switzerland \\ Thomas V \\ Perneger, \\ medical epidemiologist \\ Division of \\ Substance Abuse, \\ Department of \\ Psychiatry, \\ University Hospitals \\ of Geneva, \\ CH-1211 \\ Geneva 14 \\ Francisco Giner, \\ resident \\ Miguel del Rio, \\ fellow \\ Annie Mino, \\ head of division \\ Correspondence to: \\ Dr Perneger \\ perneger@cmu. \\ unige.ch \\ BMJ 1998;317:13-18
}


a psychiatrist, an internist, a social worker, five nurses, and a secretary.

Patients attended usually three times daily. The dose of heroin was established by the psychiatrist on the basis of patients' needs. Patients were instructed in safe intravenous injection practices and could inject the drug themselves. After the injection patients were observed for about 30 minutes. If a patient was intoxicated on arrival the usual dose was halved. Oral opiates (methadone or morphine sulphate) were introduced whenever patients wanted only one or two injections a day or if they had to travel. Patients addicted to benzodiazepines received clorazepate substitution treatment; all patients received psychological counselling, HIV prevention counselling, social and legal support services, and somatic primary care.

\section{Control treatment}

Subjects in the control group were encouraged to select any drug treatment programme available in Geneva, were enrolled immediately whenever possible, and were given priority for admission to heroin maintenance after 6 months.

\section{Outcome variables}

Outcome variables were consumption of street heroin and other drugs, frequency of overdoses, risk behaviours for HIV infection, numbers of days ill in past month, use of health services, health status, work status, living arrangements, quality of social relationships, monthly living and drug related expenditures, sources of income, and criminal behaviour. The questionnaire (unpublished, based on addiction severity index) was developed by the federal evaluation team, to which we added items to explore specifically the past 6 months, including risk behaviours for HIV infection, and the SF-36 health survey. ${ }^{15}$

Table 1 Baseline characteristics of patients randomly enrolled into heroin maintenance programme or assigned to 6 month waiting list, Geneva, 1995-6. Values are means (SD) unless stated otherwise

\begin{tabular}{|c|c|c|}
\hline Variable & $\begin{array}{l}\text { Experimental group } \\
\qquad(\mathrm{n}=27)\end{array}$ & $\begin{array}{l}\text { Control group } \\
(\mathrm{n}=24)\end{array}$ \\
\hline No $(\%)$ of men & $18(67)$ & $20(83)$ \\
\hline Age (years) & $31.1(4.7)$ & $32.8(5.1)$ \\
\hline Age at start of daily heroin use (years) & $18.4(3.2)$ & $21.5(5.8)$ \\
\hline Lifetime No of overdoses & $4.9(6.1)$ & $3.5(5.4)$ \\
\hline $\begin{array}{l}\text { No }(\%) \text { who had consumed several drugs together } \\
\text { often or all the time in past month }\end{array}$ & $19(70)$ & $13(54)$ \\
\hline \multicolumn{3}{|l|}{ Previous drug treatment episodes: } \\
\hline Detoxification & $3.9(2.8)$ & $3.5(2.5)$ \\
\hline Methadone maintenance & $3.0(1.4)$ & $3.5(2.0)$ \\
\hline Residential & $1.2(1.5)$ & $0.7(1.2)$ \\
\hline \multicolumn{3}{|l|}{ No (\%) with lifetime medical history: } \\
\hline Hepatitis (any type) & $15(56)$ & $14(58)$ \\
\hline HIV infection & $4(15)$ & $3(12)$ \\
\hline AIDS & $1(4)$ & $1(4)$ \\
\hline Severe depression & $22(82)$ & $14(58)$ \\
\hline Severe anxiety or stress & $25(93)$ & $15(62)$ \\
\hline Problem controlling violent behaviour & $19(70)$ & $8(33)$ \\
\hline Suicide attempt & $18(67)$ & $9(38)$ \\
\hline No (\%) who had ever practised commercial sex & $7(26)$ & $5(21)$ \\
\hline No (\%) unemployed for $>12$ months or never worked & $21(78)$ & $17(71)$ \\
\hline No (\%) who finished compulsory schooling & $18(67)$ & $16(67)$ \\
\hline
\end{tabular}

\section{Analysis}

The trial was analysed on an intention to treat basis. For continuous outcome variables we assessed changes over time by the Wilcoxon matched pairs test and differences between groups in change scores by the Mann-Whitney U test. ${ }^{16}$ For dichotomous variables we used the McNemar's test for before and after comparisons ${ }^{16}$ and tested the homogeneity of McNemar's odds ratio to compare groups. ${ }^{17}$ When all changes were in the same direction we compared proportions of individual subjects who changed status. Only exact tests and confidence intervals were used.

\section{Results}

\section{Enrolment and follow up}

Only 73 heroin users (52 men and 21 women, mean age 32 years) applied between September 1995 and March 1996, and 57 were eligible. Among those who were not eligible, 12 did not inject heroin regularly, three were not Geneva residents, three refused to comply with evaluation, and one refused to give up driving. Six eligible people delayed their decision and never provided informed consent. Of 51 patients who agreed to participate, 27 were randomised to immediate and 24 to delayed admission. All experimental group patients and 22 in the control group were reassessed 196 days on average after enrolment (range 168-248); one person from the control group filled only the SF-36 questionnaire. The two remaining patients in the control group were alive at follow up but refused to cooperate.

\section{Baseline description}

Participants (table 1) were typically young men who had been injecting heroin for an average of 12 years, had attempted eight drug treatments (range 2 to 21), and had experienced four drug overdoses (range 0 to 30 ). They had a high prevalence of mental disorders and health status scores 1-2 SD below population norms. ${ }^{15}$

\section{Treatments received}

One patient allocated to the experimental group never showed up, and another requested transfer to methadone maintenance after one day on heroin. The 25 others received intravenous heroin on average on 168 out of the first 183 days (oral opiates only were given on the remaining days); 20 patients received heroin on more than $80 \%$ of treatment days. There were no medical problems with drug injections. The mean daily dose of intravenous heroin was $509 \mathrm{mg}$ (quartiles: 400, 480,630 mg/day) in one to three injections. Median dose remained stable during the trial (month 1 to 6: 460, 500, 470, 490, 500, and $480 \mathrm{mg}$ /day). Several patients said that they experienced symptoms of craving before injections but did not mind as they knew that the next dose of heroin would be delivered on time.

In addition to heroin, all patients occasionally received oral opiates, on 78 days (43\%) of 183 (range 8 to 150$)$ days. Furthermore, $16(59 \%)$ subjects received clorazepate substitution therapy (median dose $60 \mathrm{mg}$ / day).

During the 6 month follow up 19 of 21 people in the control group entered a methadone maintenance programme, six a detoxification programme, and one a 
residential programme. Duration of stay in each programme was not assessed.

\section{Use of non-prescribed drugs}

At follow up only one (4\%) subject in the experimental group - the person who was never treated but still completed the follow up questionnaire-but $10(48 \%)$ in the control group still used street heroin daily (difference 44\%; exact 95\% confidence interval 16\% to $71 \%$; table 2). All experimental patients stopped daily use of street bezodiazepines, and their frequency of overdoses decreased significantly.

\section{Health status}

No changes were seen for physical problems or admission to hospital in both groups (table 3). Among patients in the experimental group treatments for mental problems increased and days with mental health problems decreased. Self reported severe depression declined in both groups, but severe anxiety decreased only in the experimental group. Changes in difficulty in controlling violent behaviour and in the number of suicide attempts favoured the experimental group.

Use of condoms remained stable in both groups. Patients in the experimental group no longer shared injection materials (only the non-attender (above) continued this practice) and improved disinfection practices.

Health status scores improved more among experimental patients than among controls (table 4). Differences between groups in before and after changes, in SD units, were 0.54 (95\% confidence interval -0.15 to 1.23 ) for physical functioning, 0.45 ( -0.40 to 1.29$)$ for role-physical, $0.18(-0.63$ to 0.98$)$ for bodily pain, 0.14 ( -0.08 to 0.37$)$ for general health, 0.22 ( -0.17 to 0.62 ) for vitality, 0.65 (0.03 to 1.26 ) for social functioning, 0.95 (0.11 to 1.79$)$ for roleemotional, and $0.58(0.07$ to 1.10$)$ for mental health.

\section{Social functioning}

Housing situation improved in both groups (table 5). Both groups remained stable in their marital situation
Table 2 Impact of heroin maintenance programme on drug use, Geneva, 1995-6.Values are numbers (percentages) of subjects unless stated otherwise

\begin{tabular}{|c|c|c|c|c|c|}
\hline \multirow[b]{2}{*}{ Variable } & \multicolumn{2}{|c|}{$\begin{array}{c}\text { Experimental group } \\
(\mathrm{n}=27)\end{array}$} & \multicolumn{2}{|c|}{$\begin{array}{l}\text { Control group } \\
(\mathrm{n}=21)\end{array}$} & \multirow{2}{*}{$\begin{array}{c}\text { P valueł for } \\
\text { difference } \\
\text { between } \\
\text { groups }\end{array}$} \\
\hline & Baseline & Follow upt & Baseline & Follow upt & \\
\hline \multicolumn{6}{|l|}{ Use of street heroin in past month: } \\
\hline None & 0 & $21(78)$ & 0 & $7(33)$ & \\
\hline Occasionally & 0 & $5(19)$ & $2(10)$ & $4(19)$ & \\
\hline Daily & $27(100)$ & $1(4)^{\star \star \star} \S$ & $19(90)$ & $10(48)^{\star \star \star} \S$ & $0.002 \uparrow$ \\
\hline \multicolumn{6}{|l|}{ Daily use in past month: } \\
\hline Alcohol & $6(22)$ & $5(19)$ & $3(14)$ & $4(19)$ & 1.00 \\
\hline Tobacco & $25(93)$ & $26(96)$ & $21(100)$ & $20(95)$ & 1.00 \\
\hline Hashish/cannabis & $6(22)$ & $4(15)$ & $1(5)$ & $3(14)$ & 0.49 \\
\hline Cocaine & $1(4)$ & $1(4)$ & $2(10)$ & $2(10)$ & 1.00 \\
\hline Barbituratest† & $4(15)$ & $2(7)$ & $3(14)$ & $3(14)$ & 1.00 \\
\hline Benzodiazepines†† & $12(44)$ & $0^{* \star \star}$ & $9(43)$ & $7(33)$ & 0.049 \\
\hline Opiates other than heroin†† & $2(7)$ & 0 & $1(5)$ & 0 & 1.009 \\
\hline $\begin{array}{l}\text { At least one overdose in past } \\
6 \text { months }\end{array}$ & $13(48)$ & $4(15)^{*}$ & $8(38)$ & $6(29)$ & 0.48 \\
\hline $\begin{array}{l}\text { Mean (SD) No of overdoses in } \\
\text { past } 6 \text { months }\end{array}$ & $1.0(1.5)$ & $0.2(0.6)^{\star \star}$ & $0.8(1.7)$ & $0.6(1.4)$ & 0.29 \\
\hline \multicolumn{6}{|c|}{ 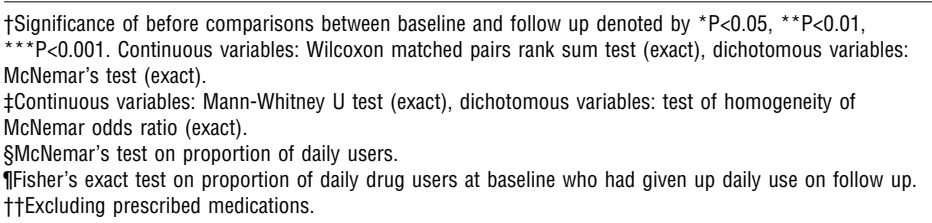 } \\
\hline
\end{tabular}

and occupational status and both developed more social ties outside the drug scene. Both reported slightly better relationships with their family and social circle (not shown).

Dependency on "street life" decreased sharply in the experimental group, less so in the control group. Charges for offences related to drug and property decreased in experimental patients and increased in the control group.

Legal income (work, loans, social benefits) remained stable in both groups (table 6). Income from illegal activities (dealing drugs, commercial sex, theft) decreased significantly in experimental patients. In particular, monthly income from dealing drugs went from $£ 1163$ to none in the experimental

Table 3 Impact of heroin prescription programme on health problems, use of services, and HIV related behaviours, Geneva, 1995-6. Values are numbers (percentages) of subjects unless stated otherwise

\begin{tabular}{|c|c|c|c|c|c|}
\hline \multirow[b]{2}{*}{ Variable } & \multicolumn{2}{|c|}{ Experimental group ( $\mathrm{n}=27$ ) } & \multicolumn{2}{|c|}{ Control group $(\mathrm{n}=21)$} & \multirow{2}{*}{$\begin{array}{c}P \text { value } \neq \text { for } \\
\text { difference between } \\
\text { groups }\end{array}$} \\
\hline & Baseline & Follow upt & Baseline & Follow upt & \\
\hline Mean (SD) No of days with physical health problem in past 30 days & $7.7(10.2)$ & $7.3(10.7)$ & $4.6(8.5)$ & $10.3(11.4)$ & 0.15 \\
\hline Treated by physician for physical problem in past 6 months & $16(59)$ & $18(67)$ & $10(48)$ & $11(55)$ & 1.00 \\
\hline Mean (SD) No of days with mental health problem in past 30 days & $13.8(11.8)$ & $6.1(9.9)^{\star *}$ & $12.2(11.2)$ & $7.1(10.7)$ & 0.54 \\
\hline Treated by physician for mental problem in past 6 months & $4(15)$ & $15(56)^{\star \star *}$ & $5(24)$ & $2(10)$ & 0.008 \\
\hline Admitted to hospital in past 6 months for physical problems & $8(30)$ & $8(30)$ & $3(14)$ & $3(14)$ & 1.00 \\
\hline \multicolumn{6}{|l|}{ Experienced in past 30 days: } \\
\hline Severe depression & $13(48)$ & $8(30)$ & $10(48)$ & $3(14)^{*}$ & 1.00 \\
\hline Severe anxiety & $22(82)$ & $12(44)^{*}$ & $9(43)$ & $9(43)$ & 0.14 \\
\hline Cognitive problems & $12(44)$ & $7(26)$ & $10(48)$ & $11(52)$ & 0.27 \\
\hline Problem controlling violent behaviour & $8(30)$ & $5(18)$ & $1(5)$ & $6(29)$ & 0.031 \\
\hline Suicide attempt in past 6 months & $6(22)$ & $1(4)$ & $3(14)$ & $4(19)$ & 0.18 \\
\hline No of suicide attempts in past 6 months & 8 & 1 & 3 & 6 & 0.022 \\
\hline Non-systematic use of condoms & $17(63)$ & $14(52)$ & $6(29)$ & $8(38)$ & 0.14 \\
\hline Shared injection materials in past 6 months & $12(44)$ & $1(4)^{\star \star}$ & $5(24)$ & $3(14)$ & 1.00 \\
\hline Did not always disinfect skin before injection in past month & $18(67)$ & $3(11)^{\star \star \star}$ & $13(62)$ & $9(43)$ & 1.00 \\
\hline
\end{tabular}

$\dagger$ Significance of comparisons between baseline and follow up denoted by ${ }^{* *} \mathrm{P}<0.01,{ }^{* \star *} \mathrm{P}<0.001$. Continuous variables: Wilcoxon matched pairs rank sum test (exact), dichotomous variables: McNemar's test (exact).

$\ddagger$ †Continuous variables: Mann-Whitney U test (exact), dichotomous variables: test of homogeneity of McNemar odds ratio (exact) 
Table 4 Impact of a heroin maintenance programme on heath related quality of life, measured by means of the SF-36 health survey, Geneva, 1995-6

\begin{tabular}{|c|c|c|c|c|c|c|c|}
\hline \multirow[b]{2}{*}{ Variable } & \multicolumn{3}{|c|}{ Experimental group $(n=27)$} & \multicolumn{3}{|c|}{ Control group ( $n=22$ ) } & \multirow{2}{*}{$\begin{array}{c}\text { P value§ for } \\
\text { difference } \\
\text { between } \\
\text { groups }\end{array}$} \\
\hline & Baseline & $\begin{array}{l}\text { Follow } \\
\text { upt }\end{array}$ & $\begin{array}{l}\text { Effect } \\
\text { size‡ }\end{array}$ & Baseline & $\begin{array}{c}\text { Follow } \\
\text { up }\end{array}$ & $\begin{array}{l}\text { Effect } \\
\text { size‡ }\end{array}$ & \\
\hline Physical functioning & 71.1 & $79.6^{*}$ & 0.40 & 79.6 & 76.6 & -0.14 & 0.13 \\
\hline Role-physical & 33.3 & $59.3^{* *}$ & 0.69 & 44.3 & 53.4 & 0.24 & 0.30 \\
\hline Bodily pain & 56.4 & $71.1^{*}$ & 0.51 & 59.6 & 69.3 & 0.34 & 0.67 \\
\hline General health & 42.2 & $53.7^{\star \star \star *}$ & 0.52 & 48.0 & 56.4 & 0.38 & 0.21 \\
\hline Vitality & 31.7 & $47.6^{\star \star \star *}$ & 0.99 & 33.4 & $45.7^{*}$ & 0.76 & 0.26 \\
\hline Social functioning & 40.3 & $64.4^{* * *}$ & 1.00 & 53.4 & 61.9 & 0.35 & 0.041 \\
\hline Role-emotional & 18.5 & $63.0^{\star \star *}$ & 1.25 & 33.3 & 43.9 & 0.30 & 0.027 \\
\hline Mental health & 36.0 & $54.4^{\star \star \star}$ & 0.97 & 42.0 & 49.3 & 0.38 & 0.025 \\
\hline
\end{tabular}

†Significance of before comparisons between baseline and follow up denoted by ${ }^{\star} \mathrm{P}<0.05$, ${ }^{* \star} \mathrm{P}<0.01$,

${ }^{* * *} \mathrm{P}<0.001$. Wilcoxon matched pairs test (exact).

fDifference divided by standard deviation at baseline.

§Mann-Whitney U test (exact). group and from $£ 1143$ to $£ 1774$ among controls $(\mathrm{P}=0.03$ for difference between groups). Living expenses changed little in either group, but patients in the experimental group reduced their drug expenses about 10 -fold whereas those in the control group continued spending similar amounts.

\section{Enrolment of controls at follow up}

Unexpectedly, only nine (38\%) of 24 controls enrolled in the heroin maintenance programme at follow up. Of those who declined, most were successfully treated in methadone maintenance programmes. Main reasons for not wanting to start heroin maintenance were a satisfactory personal situation and the desire to stop injecting drugs.

Table 5 Impact of heroin maintenance programme on social integration and illegal activities, Geneva, 1995-6. Values are numbers (percentages) unless stated otherwise

\begin{tabular}{|c|c|c|c|c|c|}
\hline \multirow[b]{2}{*}{ Variable } & \multicolumn{2}{|c|}{ Experimental group $(\mathrm{n}=27)$} & \multicolumn{2}{|c|}{ Control group $(n=21)$} & \multirow{2}{*}{$\begin{array}{c}\text { P valueł for } \\
\text { difference between } \\
\text { groups }\end{array}$} \\
\hline & Baseline & Follow upt & Baseline & Follow upt & \\
\hline No accommodation & $7(26)$ & $0^{*}$ & $4(19)$ & $1(5)$ & $1.00 \S$ \\
\hline Has stable partner & $11(41)$ & $12(44)$ & $6(29)$ & $7(33)$ & 1.00 \\
\hline Lives with drug user & $11(41)$ & $10(37)$ & $6(29)$ & $3(14)$ & 1.00 \\
\hline All or most friends outside drug scene & $5(18)$ & $10(37)$ & $5(24)$ & $9(43)$ & 0.52 \\
\hline \multicolumn{6}{|l|}{ Occupational status: } \\
\hline Neither work nor social security & $10(37)$ & $6(22)$ & $8(38)$ & $4(19)$ & 1.00 \\
\hline Employment & $4(15)$ & $6(22)$ & $4(19)$ & $3(14)$ & 0.40 \\
\hline Social security, no employment & $13(48)$ & $15(56)$ & $9(43)$ & $14(67)$ & 0.44 \\
\hline Occupational status described as "living off the street" & $21(78)$ & $5(18)^{\star \star *}$ & $13(62)$ & $8(38)$ & 1.00 \\
\hline Mean (SD) No of days worked in past 6 months & $18.7(29.8)$ & $18.5(30.0)$ & $16.7(30.9)$ & $8.8(20.4)$ & 0.36 \\
\hline Commercial sex in past 6 months & $4(15)$ & $3(11)$ & $2(10)$ & $2(10)$ & 1.00 \\
\hline \multicolumn{6}{|l|}{ Charges in past 6 months: } \\
\hline Drug use/possession & $11(41)$ & $3(11)^{\star}$ & $2(10)$ & $8(38)$ & 0.008 \\
\hline Drug dealing & $7(26)$ & $0^{*}$ & $1(5)$ & $2(10)$ & 0.067 \\
\hline Property/theft & $7(26)$ & $1(4)^{*}$ & $2(10)$ & $5(24)$ & 0.015 \\
\hline Aggression & $3(11)$ & $1(4)$ & $1(5)$ & $1(5)$ & 1.00 \\
\hline Traffic offence & $2(7)$ & 0 & $1(5)$ & 0 & 1.00 \\
\hline Other & $3(11)$ & 0 & 0 & $3(14)$ & 0.10 \\
\hline Any charge in past 6 months & $20(74)$ & $5(19)^{\star \star *}$ & $7(33)$ & $12(57)$ & 0.0004 \\
\hline Mean (SD) total number of charges in past 6 months & $2.1(2.2)$ & $0.2(0.5)^{* * *}$ & $0.4(0.7)$ & $1.1(1.3)^{*}$ & $<0.0001$ \\
\hline
\end{tabular}

†Significance of comparisons between baseline and follow up denoted by ${ }^{*} P<0.05,{ }^{*} P<0.01,{ }^{* * *} P<0.001$. Continuous variables: Wilcoxon matched pairs rank sum test (exact), dichotomous variables: McNemar's test (exact).

†Continuous variables: Mann-Whitney $\mathrm{U}$ test (exact), dichotomous variables: test of homogeneity of McNemar odds ratio (exact).

§Fisher's exact test on proportion of subjects without accommodation at baseline who found accommodation on follow up.

Table 6 Impact of heroin maintenance programme on participants' financial situation in previous month, Geneva, 1995-6. Values are mean (SD) Swiss francs (1 Swiss franc=£0.45)

\begin{tabular}{|c|c|c|c|c|c|}
\hline & \multicolumn{2}{|c|}{ Experimental group $(\mathrm{n}=27)$} & \multicolumn{2}{|c|}{ Control group ( $n=21$ ) } & \multirow{2}{*}{$\begin{array}{c}\text { P valueł for } \\
\text { difference between } \\
\text { groups }\end{array}$} \\
\hline & Baseline & Follow up† & Baseline & Follow upt & \\
\hline \multicolumn{6}{|l|}{ Income from: } \\
\hline Work & $500(1125)$ & $513(1001)$ & $305(715)$ & $119(445)$ & 0.82 \\
\hline Loans§ & $679(1623)$ & $237(555)$ & $775(1197)$ & 590 (1319) & 0.56 \\
\hline Social benefits』 & 1069 (1037) & $1359(1120)$ & $1129(1256)$ & $1688(1147)$ & 0.63 \\
\hline Other legal & $107(387)$ & $81(250)$ & $71(327)$ & $12(55)$ & 0.66 \\
\hline Drug dealing & $2485(3150)$ & $0^{\star \star \star *}$ & 2540 (3829) & $3942(9310)$ & 0.030 \\
\hline Commercial sex & 861 (2489) & 311 (1539) & $5(22)$ & 857 (3928) & 0.76 \\
\hline Other illegal & $26(134)$ & $0^{* * *}$ & $578(1563)$ & $132(544)$ & 0.08 \\
\hline Legal income & 2356 (2298) & $2191(1316)$ & $2280(1742)$ & 2409 (1717) & 0.62 \\
\hline Illegal income & $3372(3438)$ & $311(1539)^{\star \star \star}$ & $3123(4091)$ & 4931 (10133) & 0.053 \\
\hline Living expenses & $1235(748)$ & 1481 (847) & $1068(817)$ & 1874 (1293) & 0.12 \\
\hline Expenses for drugs & $4622(3025)$ & $511(1427)^{\star \star *}$ & 5425 (4609) & 4982 (9969) & 0.039 \\
\hline
\end{tabular}

tSignificance of before comparisons between baseline and follow up denoted by ${ }^{\star} P<0.05,{ }^{\star \star} P<0.01,{ }^{\star \star \star} P<0.001$. Wilcoxon matched pairs rank sum test (exact). †Mann-Whitney $U$ test for independent samples (exact)

$\S$ From family, partner, friends, banks.

I Disability, unemployment, and other social benefits. 


\section{Discussion}

This study suggests that a heroin maintenance programme may be a feasible and effective treatment option for severely addicted opiate users. Acceptability was good, as 25 of 27 patients completed 6 months in the programme on stable doses of intravenous heroin. The existence of the programme in an urban neighbourhood caused no disturbance. Thus concerns about feasibility ${ }^{18}$ need not hamper further evaluation of heroin maintenance programmes.

The experimental programme was better than other available treatments in several respects. Patients on heroin maintenance no longer used street heroin or street benzodiazepines daily, their mental health and social functioning improved, and they committed fewer suicide attempts, derived less income from illegal activities (particularly from dealing drugs), spent less money on drugs, and committed fewer offences, particularly drug and property related offences. These results are not only significant but also important for the participants' health and social functioning.

Our results are more favourable than those of the only previous trial of heroin maintenance. ${ }^{7}$ The two studies, however, differ considerably. Hartnoll's patients were less severely addicted, received fewer supportive services, could take heroin home, and received only $60 \mathrm{mg}$ of heroin daily. Evaluation methods also differed: the British researchers relied on participant observation while we used quantitative tools.

In other outcomes, experimental patients improved over time, but the difference with patients in the control group was not significant. Examples include fewer drug overdoses, better housing, better overall health status, less severe anxiety, and better precautions against HIV. A larger trial might determine whether heroin maintenance is superior to conventional treatments in these respects. Improvements experienced by controls suggest that even addicts who failed repeatedly in the past may benefit from another trial of conventional drug treatment.

Finally, the experimental programme conferred no advantage in terms of work, legal income, commercial sex, and use of street drugs other than heroin and benzodiazepines.

\section{Limitations of study}

Our study has several limitations. Firstly, this was a small trial, similar to initial evaluations of methadone maintenance ${ }^{19-21}$ which threatens the reliability of our findings. Secondly, all outcome measures were self reported, which raises the issue of information bias. Thirdly, because this study assessed global programme effects it cannot differentiate between specific effects of heroin administration and those of other medical and social services, such as mental health care and benzodiazepine substitution. Our results do not support distribution of heroin without such services and certainly not legalisation of heroin. ${ }^{3}$ We cannot exclude that the benefits of our heroin maintenance programme were entirely attributable to these additional services. Testing the specific contribution of heroin injections would require a trial in which all services but the prescribed opiate would be identical. Nevertheless, psychosocial services alone would prob-
Key messages

- A heroin maintenance programme may be a useful treatment option for patients who do not succeed in conventional drug treatment programmes

- Patients randomly allocated to the Geneva heroin maintenance programme fared better that patients in conventional drug treatments in terms of street drug use, mental health, social functioning, and illegal activities

- Results of the trial apply only to a subgroup of severely addicted people who failed repeatedly in conventional drug treatments

- This evaluation does not distinguish between the effects of heroin itself and the effects of other medical and psychosocial services that were provided as part of the programme

- There was less demand for the heroin maintenance programme than anticipated and most control subjects declined entry into the programme at the end of the study

ably achieve little as such programmes do not retain patients in treatment. ${ }^{22}$

We imposed no specified drug treatment to subjects in the control group because only patients who failed repeatedly in conventional treatments were eligible. We expected that needs and preferences would vary and wanted to allow several different treatment attempts. This choice was consistent with our research question (can heroin maintenance improve on existing treatments?), but it restricts the generalisability of our results as "existing treatments" differ by location.

Subjects who had never undergone treatment were excluded from Swiss heroin trials to avoid enrolling patients who could benefit from conventional treatments. Restriction of eligibility to addicts who had a tendency to fail in conventional treatments, however, may bias against the control group. Thus our results do not support heroin maintenance as a first line treatment of heroin addiction. Eligibility criteria also prevented us from assessing whether a heroin maintenance programme would attract addicts who had not considered drug treatment previously.

Finally, interest in the heroin maintenance programme and enrolment in the trial were less than anticipated. Whether this was due to insufficient publicity, constraints imposed by the randomised evaluation, or lack of need requires clarification. Furthermore, only nine of 24 in the control group, all of whom had requested heroin maintenance at baseline, enrolled into the programme after 6 months. Thus self perceived need for heroin maintenance may change over time, particularly when conventional drug treatment programmes are available.

Our study did not answer all relevant questions about heroin maintenance. Further research should aim to replicate our findings in larger samples and in other populations, include outcome variables that are not self reported, explore the specific contribution of medical and psychosocial services to overall programme benefits, assess the value of alternative routes 
of heroin administration, and examine possible interactions between baseline characteristics of patients and relative benefit of heroin treatment.

Contributors: TVP (coguarantor) had ultimate responsibility for the evaluation of the programme; he proposed and finalised the evaluation design, assisted with data collection procedures and data quality control, analysed the data, and wrote the paper. FG managed the experimental programme; he assisted with study design, conducted or supervised data collection, checked quality of data, discussed implications of results, and revised the paper. MdR wrote the detailed study protocol, negotiated acceptability of randomised study with authorities, discussed implications of results, and revised the paper. AM (coguarantor) had ultimate responsibility for the experimental programme; she helped with and approved the study protocol, negotiated acceptability of randomised study with authorities, discussed implications of results, and contributed to the paper.

Funding: Federal Office of Public Health (Berne, Switzerland), Swiss National Science Foundation (Berne, Switzerland, career development grant 3233-32609.91 to TVP).

Conflict of interest: None.

1 Stimson GV, Oppenheimer E. Heroin addiction. Treatment and control in Britain. London: Tavistock Publications, 1982

Ostini R, Bammer G, Dance PR, Goodin RE. The ethics of experimental heroin maintenance. J Med Ethics 1993;19:175-82.

3 Nadelmann EA. Drug prohibition in the United States: costs, consequences, and alternatives. Science 1989·245:939-47.

4 Farrell M, Ward J, Mattick R, Hall W, Stimson GV, des Jarlais D, et al. Methadone maintenance treatment in opiate dependence: a review. $B M J$ 1994;309:997-1001.

5 Koran LM. Heroin maintenance for heroin addicts: issues and evidence. N Engl J Med 1973;288:654-60.

6 Mino A. Scientific analysis of the literature on the controlled provision of heroin or morphine [in French]. Berne: Federal Office of Public Health, 1990.
7 Hartnoll RL, Mitcheson MC, Battersby A, Brown G, Ellis M, Fleming P, et al. Evaluation of heroin maintenance in controlled trial. Arch Gen Psychiatry 1980;37:877-84.

8 Ghodse AH. Treatment of drug addiction in London. Lancet 1983;i:636-9.

9 Strang J, Gossop M. Heroin addiction and drug policy: the British system. New York: Oxford University Press, 1994.

10 Lewis E. A heroin maintenance programme in the United States? JAMA 1973;223:539-46.

11 Bammer G, Douglas RM. The ACT heroin trial proposal: an overview. Med J Austr 1996;164:690-2.

12 Sheldon T. Dutch report advises prescribing heroin for misusers. BMJ 1995;310:1625.

13 Rihs-Middel M, ed. Swiss Federal Office of Public Health. The medical prescription of narcotics. Scientific foundations and practical experiences. Bern: Hogrefe and Huber Publishers, 1996.

14 Uchtenhagen A. Diversified prescription of narcotics to heroin addicts: background, design, research plan [in German]. Schweiz Rundsch Med Prax 1994;83:931-6.

15 Jenkinson C, Coulter A, Wright L. Short form 36 (SF-36) health survey questionnaire: normative data for adults of working age. BMJ 1993;306:1437-40.

16 Armitage P, Berry G. Statistical methods in medical research. 2nd ed. Oxford: Blackwell Scientific Publications, 1987.

17 Breslow NE, Day NE. Statistical methods in cancer research. Vol 1. The analysis of case-control studies. Lyons: International Agency for Research on Cancer, 1980.

18 Dole VP. Comments on "heroin maintenance". JAMA 1972;220:1493.

19 Dole VP, Nyswander M. A medical treatment for diacetylmorphine (heroin) addiction. JAMA 1965;193:80-4.

20 Dole VP, Robinson JW, Orraca J, Towns E, Searcy P, Caine E. Methadone treatment of randomly selected heroin addicts. $N$ Engl $J$ Med 1969;280:1372-5.

21 Gunne LM, Grönbladh L. The Swedish methadone maintenance programme: a controlled study. Drug Alcohol Depend 1981;7:249-56.

22 Newman RG, Whitehill WB. Double-blind comparison of methadone and placebo maintenance treatments of narcotic addicts in Hong Kong. Lancet 1979;ii:485-8.

(Accepted 6 March 1998)

\title{
Malignant spinal cord compression: prospective study of delays in referral and treatment
}

\author{
D J Husband
}

\section{Clatterbridge \\ Centre for \\ Oncology, \\ Bebington, Wirral \\ L63 4JY \\ D J Husband, \\ consultant in clinical \\ oncology}

BMJ 1998;317:18-21

\section{Abstract}

Objectives: To examine the delay in presentation, diagnosis, and treatment of malignant spinal cord compression and to define the effect of this delay on motor and bladder function at the time of treatment. Design: Prospective study of all new patients presenting to a regional cancer centre with this condition.

Setting: Regional cancer centre.

Subjects: 301 consecutive patients.

Main outcome measures: Interval from onset of symptoms to presentation and treatment, delay at each stage of referral, and functional deterioration. Results: The median (range) delay from onset of symptoms of spinal cord compression to treatment was $14(0-840)$ days. Of the total delay, $3(0-300)$ days were accounted for by patients, 3 (0-330) days by general practitioners, 4 (0-794) days by the district general hospital, and $0(0-114)$ days by the treatment unit. Initial presentation to the regional cancer centre with symptoms of malignant spinal cord compression led to a significant reduction in delay to treatment and improved functional status at the time of treatment. Deterioration of motor or bladder function $\geqslant 1$ grade occurred at the general practice stage in $28 \%(57)$ and
$18 \%$ (36) of patients, the general hospital stage in $36 \%$ (83) and 29\% (66), and the treatment unit stage in $6 \%$ (19) and 5\% (15), respectively.

Conclusions: Unacceptable delay in diagnosis, investigation, and referral occurs in most patients with malignant spinal cord compression and results in preventable loss of function before treatment. Improvement in the outcome of such patients requires earlier diagnosis and treatment.

\section{Introduction}

Metastatic malignant spinal cord compression is a major cause of morbidity in patients with cancer and often renders a previously functioning patient bedridden or in hospital for the rest of his or her life. ${ }^{1}$ The outcome of treatment is poor, with less than half of patients retaining or regaining the ability to walk and about two fifths requiring a permanent urinary catheter. ${ }^{2}$ The most important prognostic factor for functional outcome is neurological function before treatment, with about $70 \%$ of initially ambulant patients, $30 \%$ of paraparetic patients, and $5 \%$ of paraplegic patients retaining or regaining the ability to walk. ${ }^{2}$ In one review of 1392 patients, only $32 \%$ were ambulant at treatment. ${ }^{4}$ Similarly $45 \%$ of patients 